Social Trust and Grassroots Governance in Rural China 


\title{
Social Trust and Grassroots Governance in Rural China
}

\begin{abstract}
(Abstract)
The relationship between social trust and governance has been one of the focal points of the academic and policy-making communities. Empirical studies on this relationship, however, have focused mostly on democracies. The scarcity of such studies in authoritarian countries has left many important questions unanswered: Is social trust associated with effective governance only in democratic settings? Can social trust improve the quality of governance in non-democracies as well? Drawing on data from 2005 China General Social Survey_a representative survey conducted nationwide at both the individual- and village-level in rural China, this paper attempts to answer these questions empirically by examining the relationship between social trust and the quality of governance in rural China. The findings reveal that different types of social trustparticularized trust and generalized trust — correspond with different effects in rural governance: whereas villagers' trust in people whom they knew personally was positively and significantly associated with the provision of various public goods and services, their trust in strangers had virtually no impact on rural governance.
\end{abstract}

Keywords: $\quad$ Social trust, rural governance, public goods provision, Asia. 


\section{Social Trust and Grassroots Governance in Rural China}

\section{Introduction}

Ever since the late 1950s and particularly after the rise of social capital studies, the relationship between social trust and grassroots governance has attracted enormous attention from both the academic and policy-making communities. A large part of the literature suggests that social trust, as the "lubricant of society," is indispensable for effective democratic governance at various levels. ${ }^{1}$ Subsequent empirical studies further confirm that in democratic countries, higher levels of social trust usually come in tandem with more active government and more cooperative communities, which in turn lead to better performance of grassroots governance. $^{2}$

However, in contrast to the consensus achieved in democratic settings, researchers are less certain about the relationship between social trust and governance in authoritarian countries, and different, if not contradictory, findings have been reported. Many scholars, following Dahl's proposition that "mutual trust favors polyarchy ... while extreme distrust favors hegemony," have argued that social trust is intrinsically democratic, and thus the relationship between social trust and the authoritarian system of governance is conflictual. ${ }^{3}$ Another group of scholars, however, have stated that the relationship between social trust and non-democratic systems of governance is not necessarily conflictual, but can also be complementary. ${ }^{4}$ Laitin, for example, has suggested that to argue social trust is intrinsically democratic runs the risk of conflating "democracy" with "effective institutions," and it could be well the case that social trust "is more important for effective communist institutions than democratic ones."5 
Apart from the context of varying regimes, the relationship between social trust and governance is further confounded by the multi-dimensionality of social trust. Increasingly, scholars have found that the use of the term social trust depends on the identities of participants in the trust relationship, and individuals tend to place different levels of trust in people of different relational categories. ${ }^{6}$ Different forms of social trust apparently correspond with different effects in governance. ${ }^{7}$

Unfortunately, until now few empirical studies have directly tested the relationship between the different forms of social trust and grassroots governance in authoritarian settings. ${ }^{8}$ The scarcity of such studies has left several important questions unanswered: Is social trust associated with effective grassroots governance only in democratic settings? Can social trust improve the quality of governance in non-democracies as well? If so, how do different kinds of social trust affect grassroots governance? Based on data from a representative survey conducted in rural China (see Appendix A), this study attempts to answer these questions empirically by examining the relationship between social trust and the local provision of public goods in rural China.

For at least two reasons, contemporary rural China can serve as a critical case. The first reason is that the aforementioned debates are particularly acute in the Chinese contexts. On the one hand, many scholars have argued that social distrust, either derived from China's traditional culture or caused by Mao's totalitarian rule, is pervasive in China, and this pervasive distrust makes Communist Party's (CCP) non-democratic governance possible and sustainable. ${ }^{9}$ On the other hand, studies based on cross-national surveys, such as the East Asia Barometer and the World Value Survey, have suggested that China is one of the most trusting societies in the world, ${ }^{10}$ and this large reservoir of social trust is one of the reasons that governance by the CCP 
is resilient and effective. ${ }^{11}$ Unfortunately, until now there have been virtually no empirical studies that have directly tested these contradictory views. Some scholars have even excluded China as the "China outlier" from analysis. ${ }^{12}$ Second, with regard to local governance, China has undergone rapid changes and uneven development for the past three decades. Such changes and development provide an ideal opportunity to examine the impacts of various factors on rural governance. Although many researchers have examined such factors as village elections and levels of economic development on grassroots governance,${ }^{13}$ few have incorporated social trust to explain the variations in China's rural governance. With an awareness of these factors, this study can significantly advance our understanding of the relationship between social trust and grassroots governance in non-democratic societies.

In the following parts of this paper, we introduce the unique sociopolitical environment of rural governance in China, operationalize the concept of social trust in the Chinese setting, gauge the reservoir of social trust, and explore the effects of social trust on the public goods and services provided by village governments. We then conclude with a discussion on the theoretical and political implications of the findings from this study.

\section{Rural Governance in China}

In rural China, grassroots governance has undergone dramatic changes from the Mao era until the reform era. In the Mao era, the functions of public goods provisions were largely carried out by the village party branches (VPBs). The appointed party secretaries, who also monopolized critical collective resources, often took the leading role in providing basic public goods. Therefore, throughout the pre-reform era, rural governance in China has been largely directed by the party-state. Since the onset of the post-Mao reform, this mode of rural 
governance has become increasingly unsustainable. After the decollectivization of agricultural production and abolishment of the commune system, party secretaries lost their direct control over collective properties, and as a result, their role in providing public goods has been severely weakened. ${ }^{14}$ Meanwhile, ordinary villagers were largely unable or unwilling to fill the gap in public goods provision. Therefore, the de facto retreat of the party-state in the rural affairs has created a void for rural public goods provision. As noted by Ash, "[w]ith state investment in decline and no surge in voluntary investment by peasants, infrastructural decline became a serious problem." ${ }^{15}$ Since the introduction of tax-for-fee reform (TFR), the problem has turned to be even more acute. The TFR was originally designed to reduce peasants' burdens by abolishing local fees. However, since these fees were also used to fund local public services, the actual impacts of the TFR on village governance tend to be negative. ${ }^{16}$ Indeed, rural China experienced rapid deterioration in almost all the domains of public goods and services, ranging from primary education to public health. ${ }^{17}$

In recognition of this problem, the central government has made many efforts to adapt the grassroots government system to these sociopolitical changes. ${ }^{18}$ This new grassroots system for rural areas was anchored in the Village Committee (VC). According to the Organic Law of Village Committees first promulgated in 1987, the VCs are supposed to be mass organizations of self-government at the grassroots level in the rural areas. Elected by villagers, officials of VCs are responsible for administering rural socioeconomic and political affairs, particularly public goods provision. The central government sees VCs as a critical means to rectify the deterioration of rural governance and public goods provision, since elected officials of VCs are supposed to enjoy greater support from villagers and act in a more accountable manner than the appointed cadres of the Mao era. The final promulgation of the Organic Law in 1998 marked the 
beginning of the central government's push for more autonomous VCs as a solution to the deteriorating rural governance in China. By 2004, when the survey was being conducted, most villages in China had already adopted VCs as the governing body of village affairs.

\section{Rural Public Goods Provision}

Yet, under this new grassroots government system, how well are the public goods and services provided? To answer this question, we focus on three categories of rural public goods

and services: public health, social welfare, and infrastructure. ${ }^{19}$ There are at least two reasons to focus on these categories. First, while these four categories do not exhaust all aspects of public goods provision, together they capture the major concerns of rural residents across various regions of China and have a profound impact on ordinary villagers' quality of life. The relevance and importance of these four categories to villagers' lives have been confirmed by many empirical studies of rural governance in China. ${ }^{20}$ Second, a focus on a single indicator might lead to highly biased conclusions about public goods provision. For instance, a village with abundant water resources tends to spend less on irrigation systems than a village plagued by droughts. Consequently, the multiple measures used in this study can yield a more accurate picture about the public goods provision in rural China.

In terms of specific measurements, we employ the percentage of households with tap water for public health, per capita village expenditure on social welfare (e.g., cash transferred to wubao household) in 2004, and per capita village expenditure on agricultural infrastructures (e.g., irrigation systems) (see Table 1). It should be noted that the survey did not documented itemized information about the fund sources for each project. Yet, as discussed above, China's post-Mao reforms like the TFR generate strong disincentives for local governments to provide 
public services. Consequently, VCs have to take the initiative, and they rely mainly on fund voluntarily raised by peasants. If voluntary fund are insufficient, VCs have to lobby upper-level governments and compete for limited government fund. Therefore, larger village expenditures reflect better public good provision. To further gauge the relative importance of public goods provision, we also include the ratio of total expenditure on these items to administrative cost.

Table 1 reports descriptive statistics of a set of four indicators of rural public goods. First, all four indicators of public goods provision varied substantially. Take expenditure on village agricultural infrastructures per capita, for example. Villages varied from a low of no investment at all to a high of 312.5 yuan of investment per capita, with a standard deviation of 29.8 yuan. On average, VCs spent 4.8 yuan per capita on investment in village infrastructures. Together, the mean and standard deviation suggest that the distribution of $\mathrm{VC}$ expenditure on infrastructures varies widely.

\section{[Table 1 is about here.]}

Secondly, the results presented Table 1 are consistent with the findings about rural public goods provision from other surveys conducted during the same time period. Take the percentage of households with tap water, for example. According to a report released by China's Ministry of Health, in 2004 about 50 percent of households in rural China had tap water. This statistics concurs with our finding that 46.7 percent of rural households had access to tap water. ${ }^{21}$

\section{Social Trust and Its Impacts on Governance}

\subsection{Reservoir of Social Trust in Rural China}

How trustful are Chinese rural residents? The conventional approach employed in survey-based research has been to ask respondents to determine whether "most people can be 
trusted." In a study of social trust in 55 countries, Delhey and Newton found that when this measure was used, China not only ranks more highly than any other Asian country, but also is one of the few countries that can be categorized as a high-trust society. ${ }^{22}$ However, these findings are in sharp contradiction to many China scholars' observations. ${ }^{23}$ For instance, Pye has argued that lacking "bonding at a more generalized level, ... Chinese society showed little social integration beyond family, clan, and personal relationships." ${ }^{24}$ How can we explain this discrepancy?

In fact, the contradiction between these studies reveals an important question overlooked by survey-based studies, that is, the multi-dimensionality of social trust. ${ }^{25}$ Misztal, for example, has argued that a continuum of trust exists, moving from "thick" to "thin": while thick trust originates from close personal exchanges, thin trust results from less intensive social interactions such as those of voluntary associations. ${ }^{26}$ Yet the most widely used categorization of social trust — generalized trust vs. particularized trust — was proposed by Uslaner. ${ }^{27}$ Individuals with higher levels of generalized trust have a larger radius of trust and believe "most people share common values and are willing to trust strangers who may outwardly seem quite different from themselves." 28 On the contrary, individuals with higher levels of particularized trust only people known from close and intensive personal interactions, like family members, close friends, or members of close-knit groups.

The distinction between different categories of social trust is essential to our discussion on the relationship of social trust to grassroots governance. First, although there have been few survey-based studies, scholars apparently agree that the different types of social trust may variably affect governance. For instance, it has been suggested that only generalized trust promotes governance effectiveness, ${ }^{29}$ and particularized trust either has no effect or has negative 
consequences for governance. ${ }^{30}$ Second, as noted by Sturgis and Smith, many conflicting findings in the literature of social trust stem from respondents' and researchers' non-uniform interpretations of the phrase "most people can be trusted." ${ }^{31}$ People with different socioeconomic backgrounds and life experiences may interpret "most people" in dramatically different ways. In other words, the inherently vague term "most people" used in the question fail to achieve both the reliability and validity required in cross-national studies. ${ }^{32}$

To avoid the confusion caused by over-generalized terms and undefined social categories, we adopt a set of measurements based on the different social categories of "most people." Specifically, we asked respondents the following question: "Generally speaking, would you please tell me how trustworthy these categories of people are?" The respondents were asked to assess their levels of trust in people of six important social categories in rural China: relatives and close friends (qinyou), neighbors (jinlin), non-neighbors (linju yiwai de tongcun jumin), villagers sharing the same surnames (tongcun tongxing renshhi), villagers of different surnames (tongcun fei tongxing renshhi), and strangers (moshengren). ${ }^{33}$ For each category of people, respondents were asked to assess their levels of trustworthiness on a 5-point scale, where "1" stands for "most of them cannot be trusted," and " 5 " for "most of them can be trusted."

Table 2 presents the distributions of all the items of social trust on the basis of the six social categories in rural China. We can draw three important findings from the distribution. First, the overall results of the distribution tend to confirm the views held by many China scholars: the majority of our Chinese rural respondents apparently trusted people they know personally. ${ }^{34}$ This result is a clear indication of a high level of particularized trust. Specifically, the number of respondents who indicated that either more than half or most of the members of the five non-stranger relational categories can be trusted ranges from a low of 67 percent for trust 
in non-neighboring villagers to a high of 91 percent for trust in relatives. This finding is further reinforced by the fact that the mean scores of all the five items of social trust in non-stranger categories are well above "3." Together these findings suggest that the respondents in rural China have high levels of trust in people of non-stranger categories, encompassing relatives and all the other villagers.

\section{[Table 2 is about here.]}

A second important finding that we can draw from the results presented in Table 2 is that rural residents in China are generally suspicious of people they do not know personally and are reluctant to extend their trust to strangers. Specifically, the mean score of the item of trust in strangers was only 1.88, well below " 2 ." Moreover, the survey also reveals that only less than 6 percent of all respondents agreed that either more than half or most of the strangers can be trusted. Such a finding implies that distrust in strangers is prevalent in rural China; most rural residents are not willing to extend their radius of trust to people whom they do not know personally.

Third, the juxtaposition of the two findings above clearly reveals a sharp contrast in Chinese rural residents' trust in different groups of people. This confirms our earlier suggestion regarding the complexity of social trust. Instead of being a monolithic whole, social trust differentiates into a variety of specific instances of trusts in the course of daily social interactions. We use factor analysis to sort out the latent subdimensions of social trust. The results are reported in Table 3. Two factors, composed of all the six trust items, emerge from the factor analysis. These two factors deal neatly with particularized trust and generalized trust respectively: the factor of particularized trust encompasses the five items of trust in nonstrangers (relatives, non-/neighbors, and villagers of same/different surnames); only trust in 
strangers accounted for the factor of generalized trust. Together, the two factors explain two thirds (68.4 percent) of the item variance among all the six items of social trust.

\section{[Table 3 is about here.]}

From the results of this factor analysis, two important findings stand out. First, the results presented in Table 3 confirm that the most important distinction between different types of social trust is the one between particularized trust and generalized trust. Specifically, although in this study we employ six trust items that encompass various relational categories in rural China, we ended up with only two components after the factor analysis, which is highly consistent with earlier findings reported from China and other countries. ${ }^{35}$ Hence, it is reasonable to assume that ordinary Chinese rural residents markedly differentiate between trust in fellow villagers and trust in strangers.

A second finding is that particularized trust in rural China seems to be less particularistic than many scholars have argued. ${ }^{36}$ Specifically, although the average Chinese villagers' trust in relatives was slightly higher than the other four categories of particularized trust (i.e., villagers of same surname, villagers of different surnames, neighboring villagers, and non-neighboring villagers), the gap is neither substantial nor statistically significant. In other words, the ordinary Chinese villagers generally trust their fellow villagers equally, regardless of their clan or lineage identities or whether or not the villagers are their neighbors.

The lopsidedness between particularized and generalized trust certainly can be explained by sociodemographic factors like the size of community. Huhe, for instance, finds that the village size is negatively associated with the level of particularized trust in rural China. ${ }^{37}$ Yet, many other scholars emphasize the role of nondemocratic rule. ${ }^{38}$ A defining characteristic of the Communist rule is the absorption and destruction of social groups. Through political campaigns 
like the Cultural Revolution, peasants in China have been torn from their lineages and even direct families, and the atomized masses are the easy subjects of mobilization by the party-state. Therefore, it is not surprising that peasants in China generally trust their fellow villagers equally.

\section{[Figure 1 is about here.]}

From a comparative perspective, the boundary between generalized and particularized trust can be conceptualized and thus compared as the "radius of trust." 39 As suggested by Delhey, Netwon, and Welzel, we can examine the trust radius by calculating the associations of "trust in most people" with particularized and generalized trust. ${ }^{40}$ A strong association with particularized trust then indicates a small radius of trust. Using data from the fifth wave of WVS, we are able to compare the trust radius of China in a global setting. As revealed in Figure 1, China occupies the upper left corner and is quite similar to countries like Vietnam, Thailand, and South Korea. Not only are these societies high in trust level and narrow in trust radius. More interestingly, they all have experienced or are experiencing nondemocratic rules. In light of this, an examination of the case of China can significantly advance our understanding about the relationship between social trust and grassroots governance in non-democratic settings.

\subsection{Impacts of Different Forms of Social Trust on Grassroots Governance}

Thus far, we have found that social trust is a multi-dimensional concept, encompassing two sub-dimensions - particularized trust and generalized trust. Is the provision of public goods in rural China influenced by these two types of social trust? And, if so, to what extent?

Until now there has been virtually no consensus on how different forms of social trust effect grassroots governance, not to mention in non-democratic settings. Many earlier studies, mostly conducted in the Western settings, have proposed that generalized trust, as a key 
component of bridging social capital, could improve performance of local government through a variety of channels. ${ }^{41}$ Knack, for example, suggests two possible mechanisms. ${ }^{42}$ First, trust can influence the community performance by shaping the governmental accountability. Generalized trust, with a greater emphasis on strangers, helps to broaden governmental accountability, which in turn makes government "responsive to citizens at large rather than to narrow interests."

Second, generalized trust improves performance of communities by forging the convergence of political preferences. Trusting a stranger may facilitate agreement where political preferences are polarized, which in turn may help forge various forms of sociopolitical cooperation. In light of this, one could hypothesize that generalized trust is positively associated with local public goods provision in rural China.

On the other hand, the impacts of particularized trust are found to be ambivalent. Putnam, for example, argues that particularized trust is an integral part of social capital (i.e., bonding social capital), and it is a proper balance between generalized and particularized trust that improves grassroots governance. ${ }^{43}$ However, many other scholars find that particularized trust is the "dark-side of social capital" and gives rise to malign phenomena like ethnocentricism and organized crimes. Moreover, when the democratic rule is weak, the detrimental effects of particularized trust can be further amplified. Callahan's study on elections in Thailand, for example, reveals that particularized trust in fact facilitates political corruptions like vote buying. ${ }^{44}$ Similarly in Russia, Rose finds that blat, as a form of particularized trust, severely undermines formal rules and institutions. ${ }^{45}$

However, these propositions are formulated in country-based studies, shedding little light on crossnational variations in radius of social trust. The quality of governance varies not only because of changing levels of particularized and generalized trust, but also depending on varying 
radiuses of trust. Given different trust radiuses, the same changes to particularized and generalized trust are not likely to have identical impacts on local governance. Instead of focusing solely on the absolute effects of their relative levels, we should also pay attention to the varying boundaries between particularized and generalized trust.

In rural China, particularized trust encompasses virtually every member in the village community. The large radius of particularized trust avoids its potential negative effects (e.g., social exclusion), but still renders strong positive bonding effects. Particularized trust in rural China thus can help overcome the collective action problem of voluntary investment by peasants. Different from formal institutional arrangements, social cooperation in public goods provision lacks third-party scrutiny. Therefore, how to monitor and punish the free-riders is a key problem faced by the participants of social cooperation. Particularized trust with a large radius provides an effective solution to this monitoring problem. Specifically, when individuals trust each other, fewer resources will be spent on monitoring free-riders. In addition, with a large reservoir of social trust, the risk of detection and punishment serves as a deterrent against free-riding behavior. Free-riders are not only more easily identified, but also face severe social sanctions ranging from community boycott to ostracism. In other words, with intensive particularized trust, social controls tend to be strong and misbehavior can be easily sanctioned. Anecdotal studies conducted in China suggest that, rather than generalized trust, particularized trust is strongly associated with communal cooperation. ${ }^{46}$ Jae Ho Chung, Hongyi Lai, and Ming Xia, for instance, find that when there is a large reservoir of particularized trust, villagers in rural China are more likely to cooperate with each other to provide basic public goods. ${ }^{47}$ As we noted above, few empirical studies, and even fewer analyses of nondemocratic contexts have directly addressed the impacts of particularized trust on grassroots governance. 
In sum, we develop two directional hypotheses with regard to the impacts of generalized trust and particularized trust on rural governance in China:

Hypothesis 1: Villages with higher levels of generalized trust tend to have better grassroots governance.

Hypothesis 2: Villages with higher levels of particularized trust tend to have better grassroots governance.

Our hypotheses are directional in that, as elaborated above, if the two forms of social trust render any significant influence, the influence should be positive given the particular socioeconomic environment in rural China. We find no reasons to conceive detrimental effects of social trust on rural governance.

\subsection{Control Variables}

In order to test the independent effects of the two types of social trust on rural public goods provision, this study incorporates five sets of sociopolitical and socioeconomic factors as control variables. Specifically, these categories of control variables are formal institution (i.e., Village Representative Assembly), lineage groups as informal institutions, economic development, geographic/demographic traits, and regions (See Appendix B).

Village Representative Assembly. The introduction of grassroots democracy is widely perceived to be positively correlated with public goods provision. Besides VCs, the Organic Law also introduces the village assembly (VRAs) as a monitoring body to improve the rural governance. The village assembly, composed of ordinary villagers, is supposed to check the power of VCs, particularly on the financial issues. Therefore, the mode of selection of village 
representatives in the assembly may affect the performance of VCs. In this study, we identified the proportion of village representatives who are nominated and selected by villagers as a variable indicative of the quality of the village assembly. However, it should be noted that until now there has been no consensus on the effectiveness of VRAs.

It should be noted that constrained by the available data, our operationalization of grassroots democracy in rural China is inevitably limited. VRAs represent only one aspect of grassroots democracy and cannot be equated with its overall quality. For instance, a key factor missed in this study is role of village party branches (VPBs). As agents of the party-state, party secretaries are more responsive to upper-level governments than they are to the VCs. The prominence of the VPB in village affairs therefore may endanger village self-governance.

Lineage Groups as Informal Institutions. The quality of rural governance in China is also affected by social pressures arising from such solidary groups as lineage groups. Tsai, for instance, found that lineage groups as informal institution can strongly influence the levels of public goods provisions. ${ }^{48}$ We thus include a second set of control variables to represent the impacts of informal institutions. Specifically, we include a dummy variable to denote the existence of well-organized clans in a village. ${ }^{49} \mathrm{We}$ expect that the presence of lineage groups as informal institutions may help improve the public goods provision.

Economic Development. The level of economic development is widely perceived to be one of the determinants of public goods provisions. As the level of economic development rises, a village ought to have more resources available for improvement of public goods and services. Thus, wealthy villages are more likely to have adequate public goods and services. To gauge the level of economic development, we employ village income per capita. In addition, to capture the level of industrialization of each village, which is related to the level of economic development, 
we also incorporate a dummy variable for the existence of village enterprises, which are marketoriented and collectively owned enterprises under the purview of village governments.

Geographic and Demographic Traits. The geographic and demographic variables in this study include village population, the number of natural villages under one $\mathrm{VC}$, the education level, and the distance from the county seat. All of these variables may have some implications for public goods provision. For example, a larger population always increases demands of public goods provision. Moreover, in rural China not all villagers are leaving a common residential community. Sometime, within the jurisdiction of an administrative village there are several naturally formed small residential communities. The coexistence of several natural villages might significantly increase the costs of maintaining roads and bridges. In addition, demand for public goods provision should be higher in village where the average education level is high, since well-educated individuals tend to have higher expectations of the quality of life. Proximity to county seat might be negatively correlated with demands of better education and medical services, since individuals could easily travel to county sites for such services.

Controls at the Province Level. Regional diversity and disparity might also play a role in shaping public goods provision, since, for example, the resources and demands for public goods and services might vary by region due to their different economic, social and cultural conditions. In this study, therefore, we use three key controls at the provincial level to address the variations which result from regional differences, such as percentage of rural population, average disposable income of rural household, and province's reliance on agricultural and arable land occupation tax. Although far from being comprehensive, these provincial-level variables, we believe, can reveal important regional differences. 


\section{Results and Discussion}

In order to explore the effects of the two types of social trust on village public goods provision, we employ a multilevel approach (see Table 4). The key feature that distinguishes the multilevel model from the classical regression models is the modeling of variation between groups (in our study, the provinces). Scholars have long noticed that depending on the local context, public goods provision could vary substantially even within one country. Putnam's canonical work on Italy, for example, reveals that the different cultural and historical heritages of the North and South of Italy have fundamentally shaped the disparity of public services in the country. ${ }^{50}$ Similarly, scholars have frequently emphasized the significant impacts of the local contexts on various sociopolitical phenomena in China. ${ }^{51}$ Moreover, China's rapid but uneven economic growth has significantly increased the regional disparity, making the impacts of local contexts even more prominent. Compared to single-level, no-pooling (e.g., province- or regionbased) and pooling analyses, multilevel analysis allows for a more accurate estimation of the additive effects of both the individual and contextual correlates, and thus is more reliable than single-level analysis in exploring the correlates of public goods provision in rural China.

Specifically in this study, we adopt the Markov chain Monte Carlo (MCMC) Bayesian analysis. Unlike maximum likelihood (ML) estimation, Bayesian estimation holds no strong assumption about sampling distribution and thus is much less biased. Stegmueller's recent systematic comparison further reveals that Bayesian estimation is not only less biased but also

more rigorous (i.e. more conservative) than ML estimation. ${ }^{52}$ Moreover, to ensure the robustness of our analyses, we test the hypotheses by varying the measurement for the dependent variable (i.e., public goods provision). A combination of these strategies, we believe, renders a rigorous empirical test for the hypotheses regarding the impacts of social trust. 


\section{[Table 4 is about here.]}

Table 4 reports the results of the Bayesian estimates of the model specified above, and several important findings stand out. First, the particularized trust had a significant and positive impact on village pubic goods provision. Even when we control for generalized trust, the quality of formal institutions, informal institutions, economic development, and other demographic and geographic factors at the individual and provincial level, the estimated effect of particularized trust is still positive and significant for two out of three direct measures of public goods provision (i.e., expenditure on social welfare and agricultural infrastructure). Moreover, the findings also suggest that villages with higher levels of particularized trust tend to have a higher share of public goods expenditure (measured in social welfare and agricultural infrastructure) within their total spending. In sharp contrast, generalized trust is not significantly associated with village public goods provision. The measure of generalized trust yields no substantial impact on our four measures of public goods. These results suggest that the level of generalized trust in a village does not influence the quality of pubic goods provision.

Second, the results of this study do not support the argument that the VRAs can effectively improve public goods provision in rural China. The estimated effects of the percentage of elected village representatives are not statistically significant. These findings suggest that variations in composition of VRAs do not make a significant difference on public goods provision. This confirms some anecdotal observations about ineffectiveness of VRAs. ${ }^{53}$ As for the overall impact of grassroots democracy, we do not have a full answer to this question due to the lack of empirical data. To do so, more comprehensive operationalization of grassroots democracy is required. 
Third, the presence of lineage groups, as informal institutions, has no substantial impact on village public goods provision. Not only are the signs of the estimated effects mixed, but their estimated effects are not statistically significant. These findings call into question the thesis of the solidary group that "the right kind of social groups" is the key determinant of public goods provision. ${ }^{54}$ It is quite possible that social trust makes informal institutions effective, since most solidary groups are in fact deeply rooted in strongly particularized trust among villagers. ${ }^{55}$ Yet this requires further empirical research to untangle the relationship between social trust and informal institutions.

Fourth, the results also reveal that the levels of economic development have a significant and positive impact on public goods provision. The estimated effects of villagers' income and village-owned enterprises are positive and significant for tap water coverage. Moreover, villages with village-owned enterprises tend to spend on more social welfare. One possible explanation is that villages with village-owned enterprises can use their revenues to fund public projects like tap water system directly, and voluntary fund raising becomes unnecessary. For villagers, economic development not only increases their demands for better public goods provisions, but also provides them with more resources to meet these demands. In other words, economically more developed villages are less dependent on particularized trust to improve local governance, and thus are more likely to cultivated generalized trust. These findings, to certain extent, confirm the modernization thesis that economic development comes in tandem with profound social changes.

Last but not least, the results in Table 4 confirm our expectations about the sheer regional differences in public goods provision. Specifically, the findings reveal that provinces with lower levels of urbanization tend to have smaller tap water coverage, which in turn suggest that the 
urbanization process strongly shapes the provision of such public goods as tap water. Moreover, our analysis indicates that provinces which relied more on agricultural taxes had a lower level of public goods provision in areas such as social welfare and agricultural infrastructure. State extraction, therefore, may constrain public goods provision in rural China.

\section{Conclusions}

Grassroots governance is deeply embedded in social relations. Therefore, individuals' basic perception of each other can strongly affect various sociopolitical outcomes, and such mechanisms take place not only in democratic settings. This study finds that in China, one of most resilient authoritarian regimes in the world, the levels of social trust expressed by rural residents are strongly associated with the public goods provision at the local level. Specifically, we find that in Chinese villagers' minds, the two kinds of social trust, particularized trust and generalized trust, are clearly differentiated. In addition, these two types of social trust exert different impacts on rural governance: Whereas villagers' trust in people whom they personally know was positively and significantly associated with the provision of various public goods and services, their trust in strangers virtually has almost no impact on such provision.

The findings of this study have several important implications. First, these findings indicate that it would be misleading to assume a linear relationship between social trust and democracy. High levels of social trust not only help democracy work, but also make nondemocracies function. Moreover, since in non-democratic settings ordinary people cannot rely on formal political institutions to achieve better governance, dense trust among them seems to be an option they have. ${ }^{56}$ Thus it is reasonable to infer that the role of social trust might be even more important in non-democracies for the wellbeings of ordinary people. By the same token, 
this study calls for more research on the way in which social trust affect governance in nondemocratic settings.

Second, the empirical findings here also suggest that the roles of different types of social trust in local governance are far more complicated than we early thought. Specifically, particularized trust is not necessarily associated with "dysfunctional communities." Instead, with common interests at stake, particularized trust might be conducive to local governance. By contrast, the role of generalized trust might be overstated, particularly with regard to local governance.

Third, the important role of economic development revealed in this study points to another avenue to better grassroots governance. Economically more developed villages are not constrained by the reservoir of particularized trust to provide public services. This in turn implies that further economic development in rural China can make particularized trust increasingly irrelevant in grassroots governance. Moreover, economic modernization can also create fertile ground for the emergence of more inclusive forms of social trust (i.e., generalized trust). In the long run, the radius and level of social trust in rural China will continue to experience noteworthy changes.

Finally, the findings of this study also have important methodological implications for survey-based studies of social trust. Since social trust is an inherently multi-dimensional concept, it might be problematic to rely on a single measure to gauge social trust. To ensure the validity of comparative political studies of social trust, researchers should be more careful in selecting their specific measures. As a preliminary effort, our study is inevitably limited in its revealing of the complex nature of social trust and grassroots governance in rural China. Specifically, our retrospective factor analysis reveals that generalized trust is associated only 
with a single social category of "strangers." Such lopsidedness could affect the validity and comparability of the two measurements. In addition, constrained by the available data, our operationalized of grassroots democracy is also limited. More comprehensive studies are thus called for to explore how social trust and grassroots democracy jointly affect grassroots governance in rural China. 


\section{Endnotes}

1 See, for example, Edward C. Banfield, Moral Basis of a Backward Society (Glencoe, IL: Free Press, 1958); Ronald Inglehart, "The Renaissance of Political Culture," American Political Science Review 82, no. 4 (1988): 1203-30; Robert D. Putnam, Making Democracy Work: Civic Traditions in Modern Italy (Princeton, NJ: Princeton University Press, 1993); Partha Dasgupta, and Ismail Serageldin, ed., Social Capital: A Multifaceted Perspective (Washington, DC: World Bank, 2000).

2 Eric M. Uslaner, "Democracy and Social Capital," In Democracy and Trust, ed. Mark E. Warren (Cambridge and New York, NY: Cambridge University Press, 1999); Stephen Knack, "Social Capital and the Quality of Government: Evidence from the States," American Journal of Political Science 46, no. 4 (2002): 772-85; Anirudh Krishna, Active Social Capital: Tracing the Roots of Development and Democracy (New York, NY: Columbia University Press, 2002); Michael Woolcock, "The Rise and Routinization of Social Capital, 1988-2008," Annual Review of Political Science 13 (2010): 469-87.

3 Robert A. Dahl, Polyarchy: Participation and Opposition (New Haven, CT: Yale University Press, 1971), 151.

${ }^{4}$ Charles Tilly, Trust and Rule (New York, NY: Cambridge University Press, 2005); Susan H. Whiting, "The Mobilization of Private Investment as a Problem of Trust in Local Governance Structure," In Trust and Governance, edited by Valerie Braithwaite and Margaret Levi (New York, NY: Russell Sage, 1998); Martin King Whyte, "The Social Roots of China's Economic Development," China Quarterly, no. 144 (1995): 999-1019.

5 David D. Laitin, "The Civic Culture at 30," American Political Science Review 89, no. 1 (1995): 173.

6 See, for example, Karen S. Cook, Russell Hardin, and Margaret Levi, Cooperation without Trust? (New York, NY: Russell Sage, 2005); Patrick Sturgis and Patten Smith, "Assessing the Validity of Generalized Trust Questions: What Kind of Trust Are We Measuring?" International Journal of Public Opinion Research 22, no. 1 (2010): 74-92.

7 Robert D. Putnam, Bowling Alone: The Collapse and Revival of American Community (New York, NY: Simon and Schuster, 2000); Francis Fukuyama, Trust: The Social Virtues and the Creation of Prosperity (New York, NY: Penguin Books, 1995); Eric M. Uslaner, The Moral Foundations of Trust (Cambridge and New York, NY: Cambridge University Press, 2002); Jan W. van Deth and Sonja Zmerli, "Civicness, Equality, and Democracy a 'Dark Side' of Social Capital?" American Behavioral Scientist 53, no. 5 (2010): 631-39.

8 Although there are many studies focusing separately on social trust and governance, few have explored the relationship between the two. For example, see Jie Chen, Narisong Huhe, and Chunlong Lu, "Generalized vs. Particularized Social Capital: Social Trust and Grassroots Governance in Urban China," In Toward Better Governance in China: An Unconventional Pathway of Political Reform, ed. Baogang Guo and Dennis Hickey (Lanham, MD: Lexington Books, 2009).

9 Fukuyama, Trust; Lucian W. Pye, "Civility, Social Capital, and Civil Society: Three Powerful Concepts for Explaining Asia,” Journal of Interdisciplinary History 29, no. 4 (1999): 763-82. 
10 See, for example, Jan Delhey and Kenneth Newton, "Predicting Cross-National Levels of Social Trust: Global Pattern or Nordic Exceptionalism?" European Sociological Review 21, no. 4 (2005): 311-27; Soo Jiuan Tan and Siok Kuan Tambyah, "Generalized Trust and Trust in Institutions in Confucian Asia," Social Indicators Research 103, no. 3 (2010): 1-21.

11 Tianjian Shi, "Cultural Values and Political Trust: A Comparison of the People's Republic of China and Taiwan," Comparative Politics 33, no. 4 (2001): 401-19; Andrew J. Nathan, "Authoritarian Resilience," Journal of Democracy 14, no. 1 (2003): 6-17; Qing Yang and Wenfang Tang, "Exploring the Sources of Institutional Trust in China: Culture, Mobilization, or Performance?" Asian Politics \& Policy 2, no. 3 (2010): 415-36; Lianjiang Li, "Distrust in Government Leaders, Demand for Leadership Change, and Preference for Popular Elections in Rural China," Political Behavior 33, no. 2 (2011): 291-311.

12 Uslaner, "Democracy and Social Capital"; Christian Bjørnskov, "Determinants of Generalized Trust: A Cross-Country Comparison,” Public Choice 130, no. 1 (2007): 1-21.

13 Shuna Wang and Yang Yao, "Grassroots Democracy and Local Governance: Evidence from Rural China," World Development 35, no. 10 (2007): 1635-49.

14 Kevin J. O’Brien, "Implementing Political Reform in China's Villages," The Australian Journal of Chinese Affairs, no. 32 (1994): 33-59; Daniel Kelliher, "The Chinese Debate over Village Self-Government," China Journal, no. 37 (1997): 63-86.

15 Robert F. Ash, “The Peasant and the State," China Quarterly, no. 127 (1991): 495.

16 John James Kennedy, "From the Tax-for-Fee Reform to Abolition of Agricultural Taxes: The Impact on Township Governments in North-west China," China Quarterly, no. 189 (2007):4359.

17 See, for example, Zhao Rong and Yang Yao, "Public Service Provision and the Demand for Electric Appliances in Rural China," China Economic Review 14, no. 2 (2003): 131-41;

Yanzhong Huang, "Bringing the Local State Back In: The Political Economy of Public Health in Rural China," Journal of Contemporary China 13, no. 39 (2004): 367-90; Xiaobo Zhang and Ravi Kanbur, "Spatial Inequality in Education and Health Care in China," China Economic Review 16, no. 2 (2005): 189-204; Lily L. Tsai, "Solidary Groups, Informal Accountability, and Local Public Goods Provision in Rural China," American Political Science Review 101, no. 2 (2007): 355-72; Sato Hiroshi, "Public Goods Provision and Rural Governance in China," China: An International Journal 6, no. 2 (2008): 281-98; Martin King Whyte, ed. One Country, Two Societies: Rural-Urban Inequality in Contemporary China (Cambridge, MA: Harvard University Press, 2010).

18 Sylvia Chan, "Research Notes on Villagers' Committee Election: Chinese-Style Democracy," Journal of Contemporary China 7, no. 19 (1998): 507-21; O’Brien, "Implementing Political Reform in China's Villages"; Kelliher, "The Chinese Debate over Village Self-Government." 19 In rural China, limited fund and geographic dispersion severely constrained the construction of infrastructure, ranging from road to electrical grid. As for tap water system, villagers have to raise fund voluntarily to pay for the local water stations and the main pipelines.

20 Shenggen Fan and Xiaobo Zhang, "Infrastructure and Regional Economic Development in Rural China," China Economic Review 15 (2004): 203-14; Xiaobo Zhang, Shenggen Fan, Linxiu Zhang, and Jikun Huang, "Local Governance and Public Goods Provision in Rural China," Journal of Public Economics 88, no. 12 (2004): 2857-71; Renfu Luo, Linxiu Zhang, Jikun Huang, and Scott Rozelle, "Elections, Fiscal Reform and Public Goods Provision in Rural 
China," Journal of Comparative Economics 35, no. 3 (2007): 583-611; Wang and Yang, "Grassroots Democracy and Local Governance."

${ }^{21}$ The Ministry of Health, 2006 Yearbook of Public Health (Beijing: The Ministry of Health, 2006).

${ }^{22}$ Delhey and Newton, "Predicting Cross-National Levels of Social Trust."

${ }^{23}$ See, for example, Thomas B. Gold, "After Comradeship: Personal Relations in China since the Cultural Revolution," China Quarterly, no. 104 (1985): 657-75; Fukuyama, Trust.

${ }^{24}$ Pye, "Civility, Social Capital, and Civil Society," 767.

${ }^{25}$ Fukuyama, Trust; Aurélie Brunie, "Meaningful Distinctions within a Concept: Relational, Collective, and Generalized Social Sapital," Social Science Research 38, no. 2 (2009): 251-65; Ryan Light, "Like Strangers We Trust: Identity and Generic Affiliation Networks," Social Science Research 51, no. 1 (2015): 132-44; Markus Freitag and Richard Traunmüller, "Spheres of Trust: An Empirical Analysis of the Foundations of Particularised and Generalised Trust," European Journal of Political Research 48, no. 6 (2009): 782-803.

${ }^{26}$ Barbara A. Misztal, Trust in Modern Societies: The Search for the Bases of Social Order (Cambridge, UK: Polity Press, 1996).

${ }^{27}$ Uslaner, The Moral Foundations of Trust.

${ }^{28}$ Eric M. Uslaner and Richard S. Conley, "Civic Engagement and Particularized Trust: The Ties that Bind People to Their Ethnic Communities," American Politics Research 31, no. 4 (2003): 335.

${ }^{29}$ Knack, "Social Capital and the Quality of Government"; Uslaner, The Moral Foundations of Trust.

${ }^{30}$ Sonja Zmerli, "Applying the Concepts of Bonding and Bridging Social Capital to Empirical Research." European Political Science 2, no. 3 (2003): 68-75; van Deth and Zmerli, "Civicness, Equality, and Democracy."

31 Sturgis and Smith, "Assessing the Validity of Generalized Trust Questions."

32 Cook, Hardin, and Levi, Cooperation without Trust?

33 It should be noted that in rural China, several expressions - such as daxing, zongzu, jiazu, or zong - are used interchangeably to describe a clan/lineage group. In this survey, we use the term "xing" (which literally means "surnames"), since it commonly refers to the major clan or lineage group in a village. Xiaotong Fei, From the Soil: The Foundations of Chinese Society (Translated by Gary G. Hamilton and Wang Zheng, Berkeley and Los Angeles, CA: University of California Press, 1992); Bofeng Chen, "Society of Acquaintances: An Exploration of Social Order in Chinese Villages [Shuren Shehui: Cunzhuang zhixu jizhi de lixiangxing yanjiu]," Society [Shehui] 31, no.1 (2011): 223-41.

${ }^{34}$ See, for example, Gold, "After Comradeship"; Pye, "Civility, Social Capital, and Civil Society."

${ }^{35}$ Chen, Huhe, and Lu, "Generalized vs. Particularized Social Capital"; Anning Hu, "A Loosening Tray of Sand? Age, Period, and Cohort Effects on Generalized Trust in Reform-Era China, 1990-2007," Social Science Research 51, no. 2 (2015): 233-46; Freitag and Traunmüller, "Spheres of Trust."

36 Gold, "After Comradeship"; Pye, "Civility, Social Capital, and Civil Society"; Richard H. Solomon, Mao's Revolution and the Chinese Political Culture (Berkeley, CA: University of California Press, 1971). 
37 Narisong Huhe, "Understanding the Multilevel Foundation of Social Trust in Rural China: Evidence from the China General Social Survey," Social Science Quarterly 95, no. 2 (2014): 581-597.

38 Dylan Riley and Juan J. Fernández, "Beyond Strong and Weak: Rethinking Postdictatorship Civil Societies," American Journal of Sociology (forthcoming).

39 Jan Delhey, Kenneth Newton, and Christian Welzel, "How General Is Trust in 'Most People'? Solving the Radius of Trust Problem," American Sociological Review 76, no. 5 (2011): 786-807. 40 Ibid.

41 Peter Evans, "Government Action, Social Capital and Development: Reviewing the Evidence on Synergy," World Development 24, no. 6 (1996): 1119-32; Putnam, Bowling Alone; Robert D. Putnam and Kristin A. Goss, "Introduction," in Democracies in Flux: The Evolution of Social Capital in Contemporary Society, ed. Robert D. Putnam (New York, NY: Oxford University Press, 2002).

42 Knack, Stephen, "Social Capital and the Quality of Government: Evidence from the States," American Journal of Political Science 46, no. 4 (2002): 772-785.

43 Putnam, Robert D. Making Democracy Work: Civic Traditions in Modern Italy. Princeton, NJ: Princeton University Press, 1993.

44 William A. Callahan, "Social Capital and Corruption: Vote Buying and the Politics of Reform in Thailand," Perspectives on Politics 3, no. 3 (2005): 495-508.

45 Richard Rose, "Getting Things Done in an Antimodern Society: Social Capital Networks in Russia," In Social Capital: A Multifaceted Perspective, ed. Partha Dasgupta and Ismail Serageldin (Washington, DC: The World Bank, 2000.

46 Lijie Fang, "The Formation of Institutional Trust: A Case Study of New Rural Cooperative Medical System [Zhidu xinren de xingcheng guocheng: Yi xinxing nongcun hezuo yiliao zhidu weili]," Sociological Studies [Shehuixue Yanjiu] 14, no.2 (2009): 1-20; also see Kyle Irwin, Kimberly Edwards, and Jeffrey A. Tamburello, "Gender, Trust and Cooperation in Environmental Social Dilemmas," Social Science Research 50, no. 2 (2015): 328-342;

47 Jae Ho Chung, Hongyi Lai and Ming Xia. "Mounting Challenges to Governance in China: Surveying Collective Protestors, Religious Sects and Criminal Organizations," China Journal 56, no. Jul. (2006): 1-31; also see Joonmo Son and Nan Lin, "Social Capital and Civic Action: A Network-Based Approach," Social Science Research 37, no. 2 (2008): 330-49.

48 Tsai, "Solidary Groups."

49 Melanie Manion "Democracy, Community, Trust: The Impact of Elections in Rural China," Comparative Political Studies 39, no. 3 (2006): 301-24; Kung et al., "Rural Cadres and Governance in China."

50 Putnam, Making Democracy Work.

51 Helen F. Siu, "Cultural Identity and the Politics of Difference in South China," Daedalus 122, no. 1 (1993): 19-44.

52 Daniel Stegmueller, "How Many Countries for Multilevel Modeling? A Comparison of Frequentist and Bayesian Approaches." American Journal of Political Science (forthcoming).

${ }^{53}$ Björn, "The Post-Election Administration of Chinese Villages."

54 Tsai, "Solidary Groups," 356.

55 See, for example, Elinor Ostrom, "A Behavioral Approach to the Rational Choice Theory of Collective Action," The American Political Science Review 92, no. 1 (1998): 1-22.

56 See, Rose, "Getting Things Done." 
57 Samuel Bowles and Herbert Gintis, "Social Capital and Community Governance," The Economic Journal 112, no. 483 (2002): F419-F36. 
Table 1. Summary of Dependent Variables: Rural Public Goods Provision in China

\begin{tabular}{lrrrrr}
\hline & $N$. & Min. & Max. & Mean & Std. \\
\hline $\begin{array}{l}\text { Percentage of households with tap } \\
\quad \text { water }\end{array}$ & 394 & 0 & 100 & 46.7 & 44.41 \\
$\begin{array}{l}\text { Expenditure on social welfare (RMB } \\
\quad \text { per capita) }\end{array}$ & 375 & 0 & 714.3 & 5.5 & 43.82 \\
$\begin{array}{l}\text { Expenditure on agricultural } \\
\quad \text { infrastructure (RMB per capita) }\end{array}$ & 378 & 0 & 312.5 & 4.8 & 19.78 \\
$\begin{array}{l}\text { Expenditure on administrative costs } \\
\quad(\text { RMB per capita) }\end{array}$ & 357 & 0 & 4187.9 & 32.6 & 225.4 \\
\hline
\end{tabular}


Table 2. The Distribution of Different Types of Social Trust in Rural China

\begin{tabular}{|c|c|c|c|c|c|c|c|c|c|c|c|c|}
\hline & \multicolumn{2}{|c|}{$\begin{array}{l}\text { Relatives and } \\
\text { Close Friends }\end{array}$} & \multicolumn{2}{|c|}{ Neighbors } & \multicolumn{2}{|c|}{ Non-Neighbors } & \multicolumn{2}{|c|}{$\begin{array}{c}\text { Villagers of } \\
\text { Same Surname }\end{array}$} & \multicolumn{2}{|c|}{$\begin{array}{c}\text { Villagers of } \\
\text { Diff. Surname }\end{array}$} & \multicolumn{2}{|c|}{ Strangers } \\
\hline & $\mathrm{N}$ & $(\%)$ & $\mathrm{N}$ & $(\%)$ & $\mathrm{N}$ & $(\%)$ & $\mathrm{N}$ & $(\%)$ & $\mathrm{N}$ & $(\%)$ & $\mathrm{N}$ & $(\%)$ \\
\hline $\begin{array}{l}\text { Most of them can be } \\
\text { trusted (5) }\end{array}$ & 2429 & 57.0 & 1923 & 45.0 & 1158 & 27.1 & 1390 & 32.8 & 1059 & 25.0 & 54 & 1.3 \\
\hline $\begin{array}{l}\text { More than half of them } \\
\text { can be trusted (4) }\end{array}$ & 1459 & 34.3 & 1721 & 40.3 & 1883 & 44.1 & 1877 & 44.3 & 1770 & 41.8 & 188 & 4.5 \\
\hline $\begin{array}{l}\text { Half of them can be } \\
\text { trusted (3) }\end{array}$ & 317 & 7.4 & 470 & 11.0 & 939 & 22.0 & 784 & 18.5 & 1104 & 26.0 & 862 & 20.5 \\
\hline $\begin{array}{l}\text { More than half cannot } \\
\text { be trusted (2) }\end{array}$ & 44 & 1.0 & 130 & 3.0 & 249 & 5.8 & 160 & 3.8 & 253 & 6.0 & 1184 & 28.1 \\
\hline $\begin{array}{l}\text { Most cannot be trusted } \\
\text { (1) }\end{array}$ & 10 & .2 & 26 & .6 & 41 & 1.0 & 27 & .6 & 53 & 1.3 & 1924 & 45.7 \\
\hline Mean Score & \multicolumn{2}{|c|}{4.47} & \multicolumn{2}{|c|}{4.26} & \multicolumn{2}{|c|}{3.91} & \multicolumn{2}{|c|}{4.05} & \multicolumn{2}{|c|}{3.83} & \multicolumn{2}{|c|}{1.88} \\
\hline Standard Deviation & \multicolumn{2}{|c|}{.699} & \multicolumn{2}{|c|}{.818} & \multirow{2}{*}{\multicolumn{2}{|c|}{$\begin{array}{l}.896 \\
970\end{array}$}} & \multirow{2}{*}{\multicolumn{2}{|c|}{$\begin{array}{r}.848 \\
4238\end{array}$}} & \multicolumn{2}{|c|}{.913} & \multicolumn{2}{|c|}{.970} \\
\hline N. of observations & \multicolumn{2}{|c|}{4259} & \multicolumn{2}{|c|}{4270} & & & & & \multicolumn{2}{|c|}{4239} & \multicolumn{2}{|c|}{4212} \\
\hline
\end{tabular}


Table 3. Factor Analysis of Social Trust Items

\begin{tabular}{lcc}
\hline Items & $\begin{array}{c}\text { Particularized Trust } \\
\text { Factor 1 }\end{array}$ & $\begin{array}{c}\text { Generalized Trust } \\
\text { Factor 2 }\end{array}$ \\
\hline Trust in villagers of the same surnames & .846 & \\
Trust in non-neighboring villagers & .812 & \\
Trust in neighboring villagers & .808 & \\
Trust in villagers of different surnames & .805 & .950 \\
Trust in relatives & .607 & \\
Trust in strangers & & \\
\hline
\end{tabular}

Note: Figures in this table are factor loadings of .25 or larger from the varimax rotated matrix for all factors with eigenvalues greater than 1.0. 
Table 4. Social Trust and Pubic Goods Provision in Rural China: Bayseian Multilevel Analysis

\begin{tabular}{|c|c|c|c|c|}
\hline & $\begin{array}{l}\text { Tap Water } \\
\text { Coverage }\end{array}$ & $\begin{array}{c}\text { Social } \\
\text { Welfare }\end{array}$ & $\begin{array}{l}\text { Agricul. } \\
\text { Infrastr. }\end{array}$ & $\begin{array}{l}\text { Share of } \\
\text { PG Exp. }\end{array}$ \\
\hline \multirow{2}{*}{ Particularized Trust } & -0.0191 & $0.0963^{* *}$ & $0.0472^{* *}$ & $0.0052^{* *}$ \\
\hline & $(0.0211)$ & $(0.0489)$ & $(0.286)$ & $(0.0030)$ \\
\hline \multirow{2}{*}{ Generalized Trust } & 0.0025 & 0.0284 & -0.0061 & -0.0019 \\
\hline & $(0.0062)$ & $(0.0574)$ & $(0.0132)$ & $(0.0274)$ \\
\hline \multicolumn{5}{|l|}{ Controls at the village level } \\
\hline \multirow{2}{*}{ Elected village representatives (\%) } & 0.0161 & 0.371 & 0.421 & -0.0964 \\
\hline & $(0.0253)$ & $(0.353)$ & $(0.517)$ & $(0.1732)$ \\
\hline \multirow{2}{*}{ Village election turnout rate } & -0.0120 & 0.719 & 0.652 & 0.560 \\
\hline & $(0.0203)$ & $(0.903)$ & $(0.722)$ & $(1.112)$ \\
\hline \multirow{2}{*}{$\begin{array}{l}\text { One Issue, One Discussion (“Yishi } \\
\text { Yiyi") }\end{array}$} & 0.0581 & 0.149 & 0.281 & 0.0213 \\
\hline & $(0.0340)$ & $(0.346)$ & $(0.697)$ & $(0.0391)$ \\
\hline \multirow{2}{*}{ Existence of lineage groups } & -0.0296 & -0.792 & 0.677 & 0.0242 \\
\hline & $(0.0315)$ & $(0.696)$ & $(0.492)$ & $(0.0422)$ \\
\hline \multirow{2}{*}{ Largest surname (\%) } & 0.587 & 0.492 & -0.112 & 0.619 \\
\hline & $(0.841)$ & $(0.346)$ & $(0.341)$ & $(1.352)$ \\
\hline \multirow{2}{*}{ Income per capita $(\log )$} & $0.969^{* *}$ & -0.682 & 0.0631 & 0.151 \\
\hline & $(0.580)$ & $(0.531)$ & $(0.0773)$ & $(0.683)$ \\
\hline \multirow{2}{*}{$\begin{array}{l}\text { Existence of village-owned } \\
\text { enterprise }\end{array}$} & $0.0297^{* *}$ & $0.515^{*}$ & -0.0091 & 0.0672 \\
\hline & $(0.0149)$ & $(0.304)$ & $(0.0127)$ & $(0.131)$ \\
\hline \multirow{2}{*}{ Population $(\log )$} & -0.0113 & 0.291 & 0.177 & -0.334 \\
\hline & $(0.0352)$ & $(0.312)$ & $(0.231)$ & $(0.821)$ \\
\hline \multirow{2}{*}{ Number of natural villages } & -0.0097 & 0.736 & -0.461 & $-0.0242^{* *}$ \\
\hline & $(0.0174)$ & $(0.797)$ & $(0.559)$ & $(0.0146)$ \\
\hline \multirow{2}{*}{$\begin{array}{l}\text { Distance from the site of township } \\
\text { government }(\mathrm{km})\end{array}$} & -0.0029 & -0.0531 & 0.065 & -0.0047 \\
\hline & $(0.0164)$ & $(0.0503)$ & $(0.1567)$ & $(0.0041)$ \\
\hline \multirow{2}{*}{ Literacy rate } & 0.350 & 0.927 & 0.454 & $0.482^{*}$ \\
\hline & 0.681 & $(1.544)$ & 0.397 & $(0.291)$ \\
\hline Arable land (mu per capita) & & & $\begin{array}{c}0.260 \\
(0159)\end{array}$ & $\begin{array}{l}0.0605 \\
(0.0823)\end{array}$ \\
\hline \multicolumn{5}{|l|}{ Controls at the provincial level } \\
\hline \multirow{2}{*}{ Percentage of rural residents } & $-0.119^{* *}$ & 0.107 & 0.276 & 0.149 \\
\hline & $(0.0719)$ & $(0.0925)$ & $(0.201)$ & $(0.227)$ \\
\hline \multirow{2}{*}{$\begin{array}{l}\text { Annual disposable income of rural } \\
\text { residents }\left(\times 10^{-3}\right)\end{array}$} & 0.0724 & -0.411 & -0.026 & 0.0084 \\
\hline & $(0.0452)$ & $(0.537)$ & $(0.215)$ & $(0.0277)$ \\
\hline \multirow{2}{*}{ Level of agricultural extraction ${ }^{a}$} & 0.611 & $-0.581^{* *}$ & $-0.612^{* *}$ & 0.0823 \\
\hline & $(1.162)$ & $(0.352)$ & $(0.309)$ & $(0.588)$ \\
\hline
\end{tabular}




\begin{tabular}{lcccc}
\hline Constant & $0.0549^{* * *}$ & $0.233^{* * *}$ & $0.251^{* * *}$ & $0.0601^{* * *}$ \\
& $(0.0221)$ & $(0.103)$ & $(0.0971)$ & $(0.0243)$ \\
$v_{2}$ & & & & \\
$v_{1}$ & 0.043 & 0.045 & 0.047 & 0.032 \\
\hline
\end{tabular}

Note: Entries are Bayesian multilevel coefficients (i.e., the average effects) and corresponding posterior deviations (in parentheses). Datasets includes 399 villages in 24 provincial units. ${ }^{* *} p<$ $0.05,{ }^{* * *} p<0.01$. $p$ value is calculated based on one-tailed test. We use the package of R2MLwiN from within $\mathrm{R}$ for the Bayesian MCMC estimation.

a The levels of agricultural extraction are calculated by (agricultural tax + arable land occupation tax)/total provincial revenue. 
Figure 1. Contrasting Level of Generalized Trust and Trust Radius

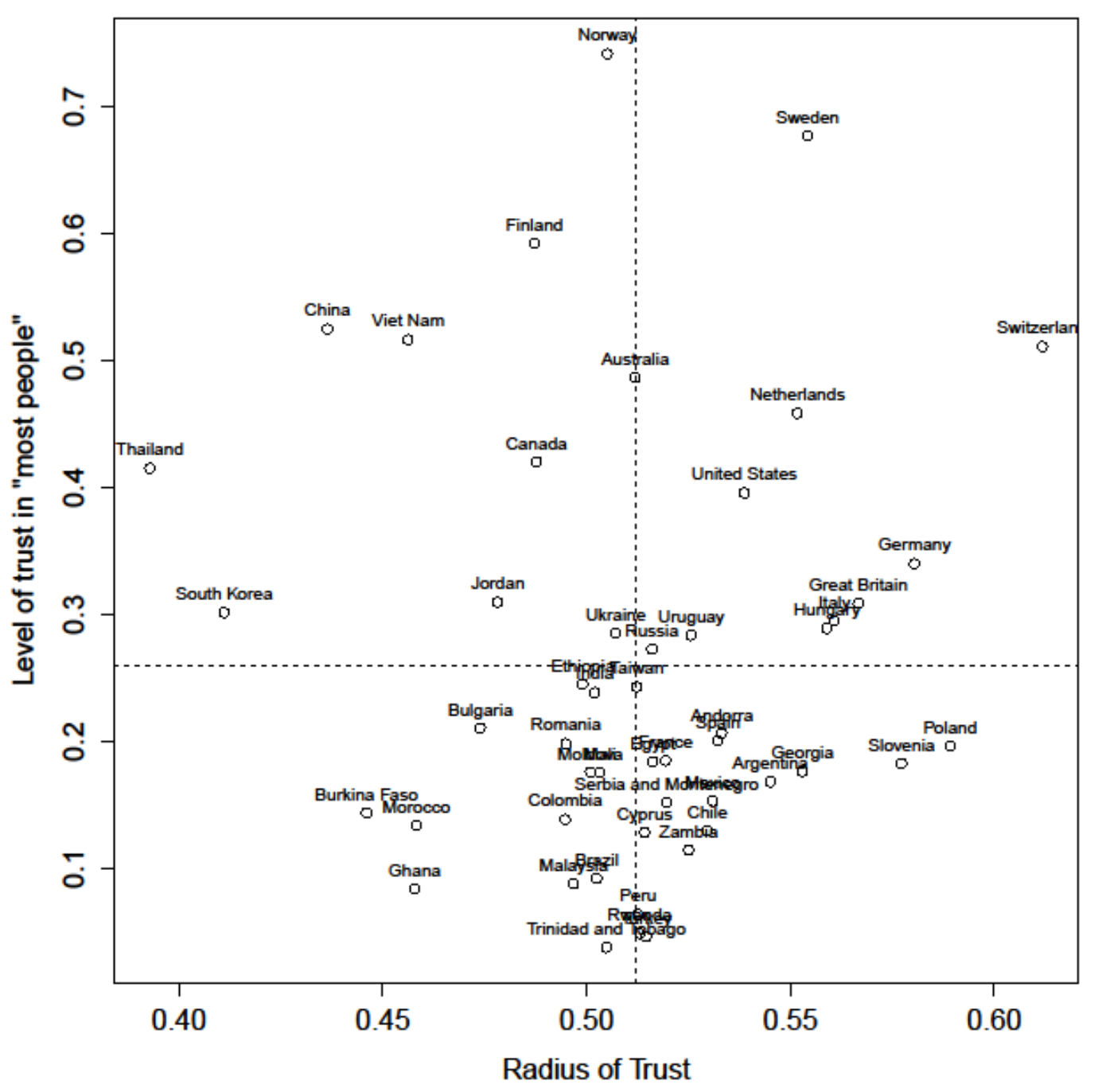

Note: Particularized trust is an additive score computed based on respondents' trust in their family, neighborhood, and people they know personally, and generalized trust is their trust in people they meet first time. For each country, an individual-level regression model has been calculated, in which the dependent variable is a respondent's trust in most people, and the independent variables are particularized and generalized trust. The regression coefficients ( $b$ 's) indicate the strength of the two associations for each country, and the difference between the two coefficients $\left(b_{\text {generalized }}-b_{\text {particularized }}\right)$ can reveal the trust radius. The dotted lines represent the global mean.

Source: WVS 5. 


\section{Appendix A: The Survey and the Sample}

The data used in this study are drawn from part of the China General Social Survey of rural residents and village governments which was carried out in twenty-four provincial units of China in 2005. This survey was conducted by one of the most reputable academic survey research organizations in China, the Public Opinion Research Institute of Renmin University of China (PORI). Embarking on a myriad of research purposes, the survey is designed to capture a comprehensive picture of rural China (with the exception of the two minority regions, Tibet and Uyghur). The samples were selected with a combination of probability proportional to size (PPS) and multi-stage sampling techniques. In the first stage, county-level units were selected within each provincial unit using the PPS technique, in which the probability of selection is proportional to the population size of the province based on China's 2000 census data. In this sampling step, a total of 92 county-level units were randomly chosen. In the second stage, a total number of 205 township-level units were randomly selected from the 92 country-level units. In the third stage, within each township-level unit, two villages were randomly selected, and a total of 410 villages were randomly selected. A sample of 4800 ordinary rural residents was randomly chosen. A total of 4,253 individual-level questionnaires were completed, with a response rate of $88.6 \%$.

Both the village-level and individual-level questionnaires were administered in the form of face-to-face interview. Graduate students who were employed were trained by project personnel to conduct the interviews. To assess the quality of the responses, interviewers were also asked to evaluate each respondent. The results of the evaluations indicated that nearly all respondents were perceived to be cooperative (98.6\%) and open (98.2\%). 


\section{Appendix B: Summary of Control Variables}

\begin{tabular}{|c|c|c|c|c|c|}
\hline Items & $N$. & Min. & $\operatorname{Max}$ & Mean & Std. \\
\hline \multicolumn{6}{|l|}{ Quality of Formal Institutions } \\
\hline Elected village representatives (\%) & 399 & 0 & 1 & 0.62 & 0.3 \\
\hline Village election turnout rate & 399 & 0 & 1 & 0.40 & 0.24 \\
\hline $\begin{array}{l}\text { One Issue, One Discussion ("Yishi } \\
\text { Yiyi") }\end{array}$ & 399 & 0 & 1 & 0.51 & 0.5 \\
\hline \multicolumn{6}{|l|}{ Lineage Groups as Informal Institutions } \\
\hline Existence of lineage groups & 399 & 0 & 1 & 0.27 & 0.45 \\
\hline Largest surname (\%) & 379 & 3 & 96 & 41.7 & 23 \\
\hline \multicolumn{6}{|l|}{ Economic Development } \\
\hline Income per capita $\left(\times 10^{-3}\right)$ & 390 & .05 & 7.40 & 1.90 & 1.24 \\
\hline Existence of village-owned enterprise & 394 & 0 & 1 & 0.15 & 0.33 \\
\hline \multicolumn{6}{|l|}{ Geographic and Demographic Traits } \\
\hline Population $\left(\times 10^{-3}\right)$ & 395 & 0.15 & 16.5 & 2.15 & 1.74 \\
\hline Number of natural villages & 395 & 0 & 70 & 4.9 & 7.62 \\
\hline Arable land $(\text { mu per capita })^{\mathrm{a}}$ & & & & & \\
\hline Literacy rate & 393 & 0.29 & 1 & 0.91 & 0.11 \\
\hline $\begin{array}{l}\text { Distance from the site of township } \\
\text { government }(\mathrm{km})\end{array}$ & 395 & 0 & 38 & 5.7 & 5.3 \\
\hline \multicolumn{6}{|l|}{ Controls at the provincial level } \\
\hline Percentage of rural residents $\mathrm{b}^{\mathrm{b}}$ & 31 & 0.22 & 0.85 & 0.673 & 0.156 \\
\hline $\begin{array}{l}\text { Annual disposable income of rural } \\
\text { residents }\left(\times 10^{-3}\right)^{\mathrm{b}}\end{array}$ & 31 & 1.72 & 7.07 & 3.16 & 1.36 \\
\hline Agricultural tax $\left(\times 10^{-9} R M B\right)^{\mathrm{c}}$ & 31 & 0.0004 & 2.511 & 0.682 & 0.700 \\
\hline $\begin{array}{l}\text { Arable land occupation tax }\left(\times 10^{-9}\right. \\
R M B)^{\mathrm{c}}\end{array}$ & 31 & 0.00045 & 2.137 & 0.387 & 0.517 \\
\hline Total provincial revenue $\left(\times 10^{-9} R M B\right)^{\mathrm{c}}$ & 31 & 1.001 & 141.8 & 37.72 & 33.84 \\
\hline
\end{tabular}

Note:

${ }^{a}$ Calculated based on the total arable land and the size of labor force in a village.

${ }^{b}$ From National Bureau of Statistics of China, China Statistical Yearbook 2005 (Beijing: China Statistics Press, 2005).

${ }^{\mathrm{c}}$ From Ministry of Agriculture, 2005 Agricultural Development Report (Beijing: China Agriculture Press, 2005). 


\section{Appendix C: Additional Analysis with A Different Set of Controls}

\begin{tabular}{|c|c|c|c|c|}
\hline & $\begin{array}{l}\text { Tap Water } \\
\text { Coverage }\end{array}$ & $\begin{array}{c}\text { Social } \\
\text { Welfare }\end{array}$ & $\begin{array}{l}\text { Agricul. } \\
\text { Infrastr. }\end{array}$ & $\begin{array}{l}\text { Share of } \\
\text { PG Exp. }\end{array}$ \\
\hline \multirow{2}{*}{ Particularized Trust } & -0.0191 & $0.0963^{* *}$ & $0.0472^{* *}$ & $0.0052^{* *}$ \\
\hline & $(0.0211)$ & $(0.0489)$ & $(0.0286)$ & $(0.0030)$ \\
\hline \multirow{2}{*}{ Generalized Trust } & 0.0025 & 0.0284 & -0.0061 & -0.0019 \\
\hline & $(0.0062)$ & $(0.0574)$ & $(0.0132)$ & $(0.0274)$ \\
\hline \multicolumn{5}{|l|}{ Controls at the village level } \\
\hline \multirow{2}{*}{ Elected village representatives (\%) } & 0.0161 & 0.371 & 0.421 & -0.0964 \\
\hline & $(0.0253)$ & $(0.353)$ & $(0.517)$ & $(0.1732)$ \\
\hline \multirow{2}{*}{ Village election turnout rate } & -0.0120 & 0.719 & 0.652 & 0.560 \\
\hline & $(0.0203)$ & $(0.903)$ & $(0.722)$ & (1.112) \\
\hline \multirow{2}{*}{$\begin{array}{l}\text { One Issue, One Discussion ("Yishi } \\
\quad \text { Yiyi") }\end{array}$} & 0.0581 & 0.149 & 0.281 & 0.0213 \\
\hline & $(0.0340)$ & $(0.346)$ & $(0.697)$ & $(0.0391)$ \\
\hline \multirow{2}{*}{ Existence of lineage groups } & -0.0296 & -0.792 & 0.677 & 0.0242 \\
\hline & $(0.0315)$ & $(0.696)$ & $(0.492)$ & $(0.0422)$ \\
\hline \multirow{2}{*}{ Largest surname (\%) } & 0.587 & 0.492 & -0.112 & 0.619 \\
\hline & $(0.841)$ & $(0.346)$ & $(0.341)$ & $(1.352)$ \\
\hline \multirow{2}{*}{ Income per capita $(\log )$} & $0.969^{* *}$ & -0.682 & 0.0631 & 0.151 \\
\hline & $(0.580)$ & $(0.531)$ & $(0.0773)$ & $(0.683)$ \\
\hline \multirow{2}{*}{$\begin{array}{l}\text { Existence of village-owned } \\
\text { enterprise }\end{array}$} & $0.0297^{* *}$ & $0.515^{*}$ & -0.0091 & 0.0672 \\
\hline & $(0.0149)$ & $(0.304)$ & $(0.0127)$ & $(0.131)$ \\
\hline \multirow{2}{*}{ Population $(\log )$} & -0.0113 & 0.291 & 0.177 & -0.334 \\
\hline & $(0.0352)$ & $(0.312)$ & $(0.231)$ & $(0.821)$ \\
\hline \multirow{2}{*}{ Number of natural villages } & -0.0097 & 0.736 & -0.461 & $-0.0242^{*}$ \\
\hline & $(0.0174)$ & $(0.797)$ & $(0.559)$ & $(0.0146)$ \\
\hline \multirow{2}{*}{$\begin{array}{l}\text { Distance from the site of township } \\
\text { government }(\mathrm{km})\end{array}$} & -0.0029 & -0.0531 & 0.065 & -0.0047 \\
\hline & $(0.0164)$ & $(0.0503)$ & $(0.1567)$ & $(0.0041)$ \\
\hline \multirow{2}{*}{ Literacy rate } & 0.350 & 0.927 & 0.454 & $0.482^{*}$ \\
\hline & 0.681 & $(1.544)$ & 0.397 & $(0.291)$ \\
\hline Arable land (mu per capita) & & & $\begin{array}{c}0.260 \\
(0.159)\end{array}$ & $\begin{array}{c}0.0605 \\
(0.0823)\end{array}$ \\
\hline \multicolumn{5}{|l|}{ Controls at the provincial level } \\
\hline \multirow{2}{*}{ Percentage of rural residents } & $-0.119^{* *}$ & 0.107 & 0.276 & 0.149 \\
\hline & $(0.0719)$ & $(0.0925)$ & $(0.201)$ & $(0.227)$ \\
\hline \multirow{2}{*}{$\begin{array}{l}\text { Annual disposable income of rural } \\
\text { residents }\left(\times 10^{-3}\right)\end{array}$} & 0.0724 & -0.411 & -0.026 & 0.0084 \\
\hline & $(0.0452)$ & $(0.537)$ & $(0.215)$ & $(0.0277)$ \\
\hline \multirow{2}{*}{ Level of agricultural extraction ${ }^{\mathrm{a}}$} & 0.611 & $-0.581^{* *}$ & $-0.612^{* *}$ & 0.0823 \\
\hline & $(1.162)$ & $(0.352)$ & $(0.309)$ & $(0.588)$ \\
\hline \multirow{2}{*}{ Constant } & $0.0549^{* * *}$ & $0.233^{* * *}$ & $0.251^{* * *}$ & $0.0601^{* * *}$ \\
\hline & $(0.0221)$ & $(0.103)$ & $(0.0971)$ & $(0.0243)$ \\
\hline
\end{tabular}




\begin{tabular}{llllc}
\hline$v_{2}$ & 0.043 & 0.045 & 0.047 & 0.032 \\
$v_{1}$ & 0.114 & 0.102 & 0.092 & 0.108 \\
\hline
\end{tabular}

Note: Entries are Bayesian multilevel coefficients (i.e., the average effects) and corresponding posterior deviations (in parentheses). Datasets includes 399 villages in 24 provincial units. ${ }^{* *} p<$ $0.05,{ }^{* * *} p<0.01$. $p$ value is calculated based on one-tailed test. We use the package of R2MLwiN from within $\mathrm{R}$ for the Bayesian MCMC estimation.

a The levels of agricultural extraction are calculated by (agricultural tax + arable land occupation tax)/total provincial revenue. 